Egypt. Acad. J. Biolog. Sci., 11(2): 49- 56 (2019)

Egyptian Academic Journal of Biological Sciences

D. Histology \& Histochemistry

ISSN 2090 - 0775

http://eajbsd.journals.ekb.eg

\title{
Sonographic Study of Normal Uterine Size in Reproductive and Postmenopausal Age in Iraqi Women and related with Parity
}

\author{
Sameeah mejbil hamad'; Samira. A.H. Abdullah²; and abdul-Jabar Mahdi \\ jameel $^{2}$. \\ 1-Anbar University, college of medicine. Anatomy department \\ 2-Tikrit University, college of medicine. Anatomy department. \\ E.Mail : sameeahalgenabi@gmail.com
}

\section{ARTICLE INFO}

Article History

Received:15/10/2019

Accepted:20/11/2019

\section{Keywords:}

Uterus

dimension, sonography, endometrial thickness
ABSTRACT

Aim: The study included sonographic assessment of normal uterine size in non-gravid adult females at reproductive and postmenopausal women and its relation with parity. The anatomical variations of uterus particularly those concerning the body of uterus are well Known in medical literature. Data on uterine dimensions in parous (prim parous or multiparous) and nulliparous women are vital for public health consideration as the presence of uterine pathology effectively reflects the status of fertility and other gynecological condition in general. The last few decades, sonography has become the most important imaging modality for the study of the uterine pathology The estimation of uterine size has been widely reported by several authors from different parts of the world. Material and methods: this study included 150 non gravid female subjects were distributed into five age groups A(20-29), B(30-39), C (40-49), D(50-59), E(60-69), each group was divided into nulliparous, primiparous and multiparous women were examined sonographically because of abdominal or pelvic problem unrelated to uterus. All groups were subjected to transabdominal technique of uterine examination with a $3.5 \mathrm{MHZ}$ transducer. The length, width and anteroposterior diameter of uterus were calculated. The uterine volume was calculated using ellipsoid algorithm. These dimensions correlated with age and parity status of each study groups.

Results: The length means increased at 20-49 age and decrease in 49-69 age. Increase the total means of the length of each group was related to parity, nulliparous $(5.68 \pm 1.24)$, primiparous $(6.15 \pm 1.72)$ and multiparous (7.28 \pm 1.33 ). Depth and width showed mild significant differences between study age groups. Width and depth were recorded increase related to party in all study groups. Uterus volume of uterus decreased with age groups, while total uterus volume increased in multiparous than the primiparous and nulliparous women. Means endometrial thickness was decreased with age groups and total means correlated with parity, in nulliparous (5.46 \pm 2.59$)$, primiparous (5.51 \pm 3.13$)$ and multiparous (6.35 \pm 3.07$)$

Conclusion: Present study the uterine length and total volume showed clear increase with age and correlated with parity, while the width and depth show little changes with age but clear changes related to parity. The endometrial thickness was decreased with age and increased significantly with parity. 


\section{INTRODUCTION}

The uterus is the most important part of female reproductive organ which is responsible for several reproductive functions, including menstruation, implantation, gestation, labor, and delivery (Merz E, et al., 1995). It is effected by hormonal milieu of the body, which allows adaptation to different stages of a women's reproductive life. The uterus adjusted to reflect changes in ovarian steroid production during the menstrual cycle and displays rapid growth and specialized contractile activity during pregnancy and childbirth. It can also remain in relatively quiescent state during the prepubertal and postmenopausal years (Milli AB, et al., 2013). Ultrasonography is most frequently used image investigation in the assessment of the female genital tract (Mihu D and Mihu C.M., 2011). Knowledge of the normal uterine dimensions of the uterus is important for assessing the health status of women and for detection the risk of developing some of the many diseases seen by gynecologists and obstetricians (Ezmaelzadeh S.et al., 2004). Determination of the normal size of uterus is most important for gynecologist to predict the development of several diseases such as uterine myoma (fibroid), adenomyosis, uterine neoplasms (Danddolu V. et al., 2010). .It is also used to detected congenital abnormalities. The sonography method has many advantages, simple, quick, accurate, reliable, harmless, and invasive procedure (Testa AC, Bourne TH. 2009), and permits multi-sectional scanning of this organ and is nonexpensive (Timor-tritsch IE, et al., 1994).

\section{MATERIALS AND METHOD}

Transabdominal sonography was performed using the commercially available real-time US machine minidary Digi prince dP8800
(Shenzhen, China). This was achieved using a $3.5 \mathrm{MHz}$ sector transducer, with acoustic gel as a coupling medium, thus avoiding inherent interference by abdominal wall skin and transducer.This study was performed at the period from $30 / 1 / 2018$ to $30 / 2 / 2019$. Estimated number of subjects was 150 . Subjects were instructed to drink about 500$1000 \mathrm{ml}$ of water to promote diuresis and to refrain from micturition until the examination. All subjects were scanned in the supine position in both longitudinal and transverse planes and uterine size determined by three measurements obtained directly from frozen image for each of the following parameters using an in-built caliper. The subjects were divided into three groups dependent on parity: nulliparous (have no child), primiparous (having one child) and multiparous (having $\geq 2$ children). Each one occupied five age groups included: (20-29), (30-39), (40-49), (50-59), (6069). Data were analyzed using SPSS software, mean, stander deviation, LSD for least significant differences and correlation coefficient was used to measure the strength of the association between variables.

\section{RESULTS}

The total mean of uterus length in nulliparous (5.68 \pm 1.24$)$. Table (1) and Fig(1) revealed the increase of the length with age at 20-39 years and decrease in 40-69, and show significant differences of length with age at $\mathrm{p}<0.05$ and show total width means and Antero-posterior diameter (3.95 \pm 0.78$)$, $(\quad 4.02 \pm 0.68)$. Width appeared slightly increase with age from 20-49 while decreased at age 5069 and appeared significant differences $(\mathrm{p}<0.05)$. Antero-posterior diameter decreased with age but no significant differences were seen. The total means of uterus volume was (47.47 \pm 23.09$)$. The uterus volume increased with age (20-49) while it was decreased with age (50-69) and 
was significant differences at $\mathrm{p}<0.05$. Endometrial thickness was decreased with age and total mean $(5.46 \pm 2.59)$, and showed significant relation with age at $(\mathrm{p}<0.05)$.

Table1:Sonographic parameters measurements of nulliparous women related with age

\begin{tabular}{|c|l|l|l|l|l|}
\hline $\begin{array}{c}\text { Age } \\
\text { groups }\end{array}$ & Length/cm & Width/cm & $\begin{array}{c}\text { Antero- } \\
\text { posterior/cm }\end{array}$ & Volume/cm & $\begin{array}{c}\text { Endo. } \\
\text { Thickness/cm }\end{array}$ \\
\hline $20-29$ & $\mathbf{6 . 1 6} \pm \mathbf{0 . 4 9}$ & $\mathbf{3 . 7 5} \pm \mathbf{0 . 8 0}$ & $\mathbf{4 . 2 0} \pm \mathbf{0 . 8 0}$ & $\mathbf{4 9 . 7 1} \pm \mathbf{2 0 . 2 9}$ & $\mathbf{7 . 7 0} \pm \mathbf{1 . 7 1}$ \\
\hline $\mathbf{3 0 - 3 9}$ & $\mathbf{6 . 5 4} \pm \mathbf{1 . 0 4}$ & $\mathbf{4 . 5 9} \pm \mathbf{0 . 9 2}$ & $\mathbf{4 . 8 0} \pm \mathbf{0 . 5 6}$ & $\mathbf{7 5 . 0 4} \pm \mathbf{3 7 . 4 6}$ & $\mathbf{7 . 4 2} \pm \mathbf{1 . 0 9}$ \\
\hline $40-49$ & $\mathbf{5 . 4 2} \pm \mathbf{1 . 8 2}$ & $\mathbf{3 . 9 9} \pm \mathbf{0 . 3 9}$ & $\mathbf{4 . 1 1} \pm \mathbf{0 . 4 0}$ & $\mathbf{6 6 . 1 3} \pm \mathbf{3 4 . 0 7}$ & $\mathbf{4 . 9 7} \pm \mathbf{2 . 2 8}$ \\
\hline $\mathbf{5 0 - 5 9}$ & $\mathbf{4 . 9 3} \pm \mathbf{0 . 7 7}$ & $\mathbf{3 . 6 7} \pm \mathbf{0 . 5 8}$ & $\mathbf{4 . 1 0} \pm \mathbf{0 . 9 6}$ & $\mathbf{2 5 . 4 \pm 1 9 . 5 2}$ & $\mathbf{3 . 7 2} \pm \mathbf{0 . 9 0}$ \\
\hline $60-69$ & $\mathbf{4 . 8 3} \pm \mathbf{0 . 8 9}$ & $\mathbf{3 . 5 0} \pm \mathbf{0 . 4 7}$ & $\mathbf{3 . 0 7} \pm \mathbf{0 . 6 2}$ & $\mathbf{2 1} \pm \mathbf{8 . 9 7}$ & $\mathbf{2 . 1 3} \pm \mathbf{1 . 1 6}$ \\
\hline Total & $\mathbf{5 . 6 8} \pm \mathbf{1 . 2 4}$ & $\mathbf{3 . 9 5} \pm \mathbf{0 . 7 8}$ & $\mathbf{4 . 0 2} \pm \mathbf{0 . 6 8}$ & $\mathbf{4 7 . 4 7} \pm \mathbf{2 3 . 0 9}$ & $\mathbf{5 . 4 6} \pm \mathbf{2 . 5 9}$ \\
\hline
\end{tabular}

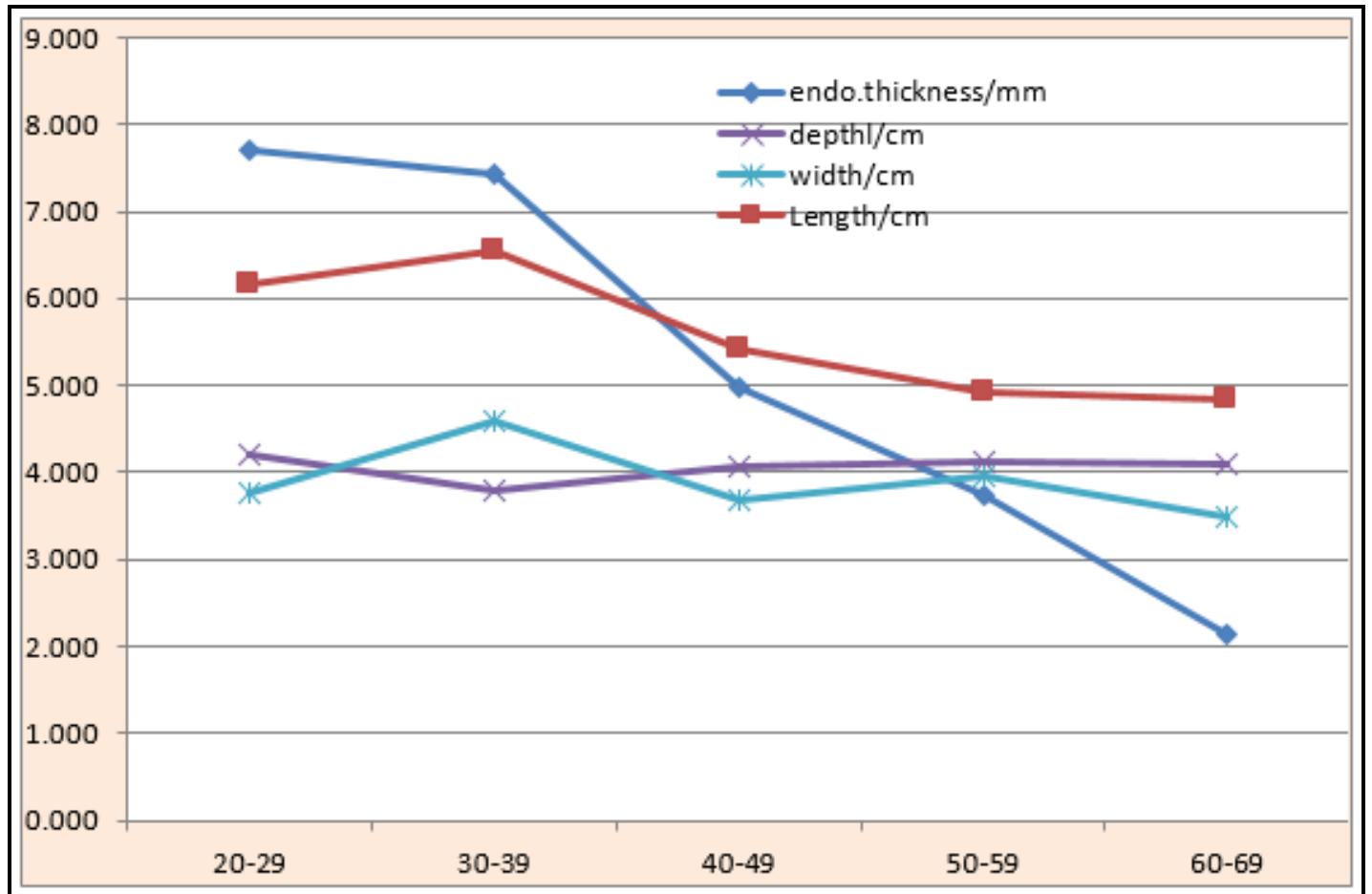

Fig.1: Graphical distribution of length, width, AP and endometrial, the thickness of nulliparous women

Table (2) and Fig (2) show the distribution of uterus dimensions, volume and endometrial thickness of primiparous women. The total length means was $(6.15 \pm 1.72)$, Width (4.05 \pm 0.68$)$, AP (3.75 \pm 0.69$)$, Volume (3.75 \pm 0.69$)$, Endometrial thickness $(5.51 \pm 3.13)$. The length was shown increased at reproductive age (2040)and then decreased with progressive age with significant differences at $\mathrm{p}<0.05$, while the width was recorded not clear changes related with age and non-significant differences was obvious between age groups and anteroposterior diameter and volume were recorded clear changes related with age with significant difference at $\mathrm{p}<0.05$. Endometrial thickness was increased at age (20-39) and then was shown decreased gradually with progressive age with significant differences at $(\mathrm{p}<0.05)$. 
Table 2: Sonographic parameters measurement of primiparous women related with age

\begin{tabular}{|l|l|l|l|l|l|}
\hline $\begin{array}{c}\text { Age } \\
\text { groups }\end{array}$ & Length/cm & Width/cm & $\begin{array}{c}\text { Antero- } \\
\text { posterior/cm }\end{array}$ & Volume/cm3 & End .thickness/cm \\
\hline $20-29$ & $7.42 \pm 0.85$ & $4.4 \pm 0.48$ & $4.16 \pm 0.85$ & $64.00 \pm 20.70$ & $7.50 \pm 3.41$ \\
\hline $30-39$ & $7.77 \pm 1.12$ & $4.89 \pm 0.72$ & $4.02 \pm 0.40$ & $68.29 \pm 17.42$ & $\mathbf{8 . 0 2} \pm 1.84$ \\
\hline $40-49$ & $6.39 \pm 1.12$ & $4.00 \pm 0.91$ & $3.31 \pm 0.33$ & $43.72 \pm 23.66$ & $3.03 \pm 1.65$ \\
\hline $50-59$ & $4.32 \pm 0.59$ & $3.97 \pm 0.89$ & $3.49 \pm 0.65$ & $28.90 \pm 8.87$ & $2.89 \pm 1.08$ \\
\hline $60-69$ & $\mathbf{3 . 4 1} \pm 0.59$ & $3.79 \pm 0.38$ & $3.37 \pm 0.46$ & $\mathbf{2 9 . 8 3} \pm 7.48$ & $\mathbf{3 . 6 7} \pm 0.79$ \\
\hline Total & $\mathbf{6 . 1 5} \pm 1.72$ & $\mathbf{4 . 0 5} \pm 0.68$ & $3.75 \pm 0.69$ & $\mathbf{5 0 . 2 4} \pm 23.75$ & $\mathbf{5 . 5 1} \pm 3.13$ \\
\hline
\end{tabular}

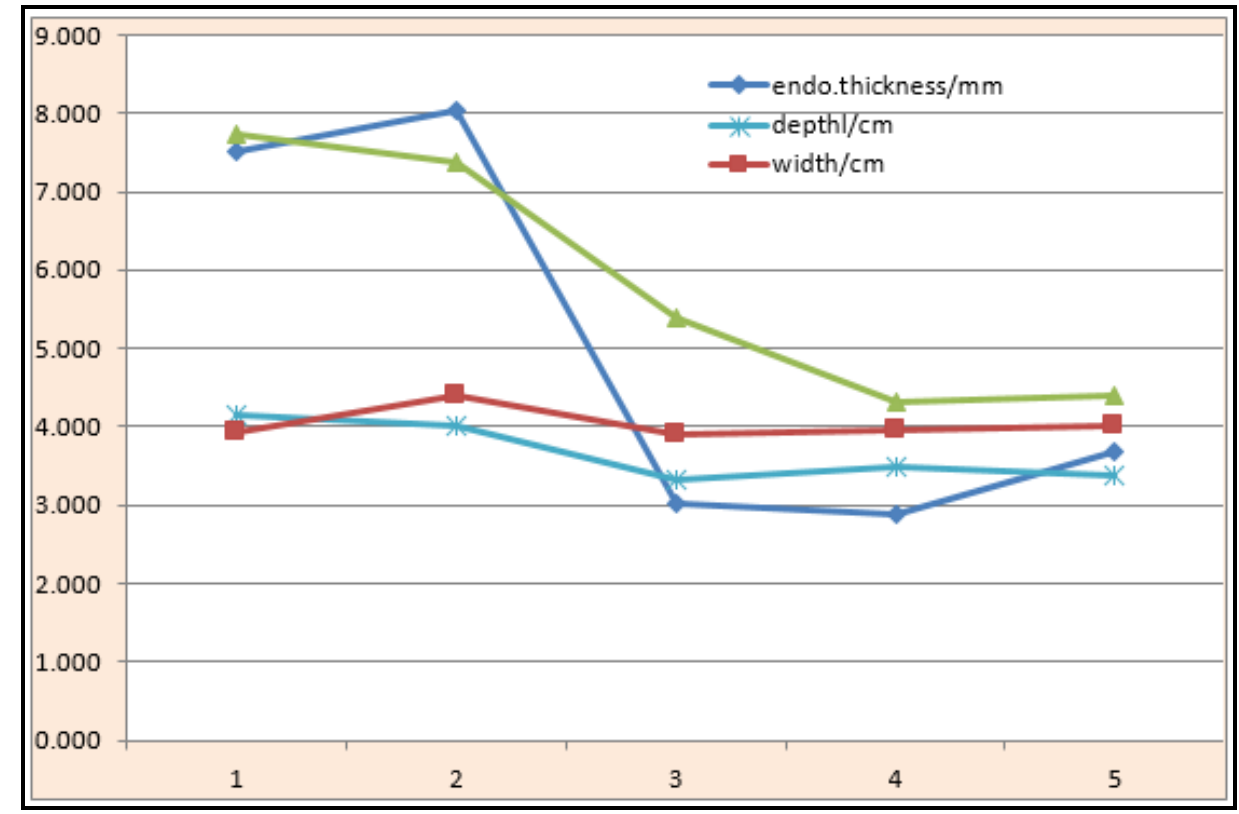

Fig.2: Graphical distribution of parameters (Length, width, endometrial thickness) of primiparous women.

Distribution of measurements of multiparous women show in table (3) and Fig (3). Total means of length (7.28 \pm 1.33$)$, Width $\quad(4.06 \pm 0.91)$, Antero-posterior diameter (4.58 \pm 0.95$)$, Volume $\quad(72.11 \pm 39.05) \quad$ and endometrial thickness $(6.35 \pm 3.07)$. The length and volume revealed of increase with age (20-49) and decreased at age (49-69) with significant differences at $\mathrm{p}<0.05$. width showed slightly increase at age (20-49) and decrease at( 50-69) and was no significant differences between age groups were clear. Antero-posterior diameter shown changes with age (increase at age (20-49) and decrease at (49-69) with significant differences at $\mathrm{p}<0.05$. Endometrial thickness appeared clear gradual decrease with age and was significant $(\mathrm{p}<0.05)$. The present study stated the dimensions of uterus varies between reproductive and postmenopausal age groups. (Fig4) and Fig (5).

Table 3: Sonographic parameters measurements of multiparous related to age

\begin{tabular}{|c|c|c|c|c|c|}
\hline $\begin{array}{c}\text { Age } \\
\text { groups }\end{array}$ & Length & width & $\begin{array}{c}\text { Antero- } \\
\text { posterior }\end{array}$ & Volume & $\begin{array}{c}\text { End. } \\
\text { Thickness }\end{array}$ \\
\hline $20-29$ & $7.41 \pm 0.74$ & $4.09 \pm 0.65$ & $4.66 \pm 0.79$ & $74.56 \pm 27.38$ & $7.28 \pm 2.13$ \\
\hline $30-39$ & $8.04 \pm 1.17$ & $4.58 \pm 0.80$ & $4.80 \pm 1.17$ & $86.97 \pm 48.85$ & $7.21 \pm 2.31$ \\
\hline $40-49$ & $7.68 \pm 1.44$ & $4.30 \pm 0.90$ & $4.67 \pm 0.89$ & $83.82 \pm 31.94$ & $6.70 \pm 3.22$ \\
\hline 50-59 & $6.62 \pm 1.13$ & $3.63 \pm 1.01$ & $4.24 \pm 1.07$ & $54.30 \pm 40.97$ & $5.64 \pm 3.64$ \\
\hline $60-69$ & $5.52 \pm 0.55$ & $3.06 \pm 0.52$ & $4.22 \pm 0.58$ & $35.82 \pm 10.09$ & $2.96 \pm 2.87$ \\
\hline Total & $7.28 \pm 1.33$ & $4.06 \pm 0.91$ & $4.58 \pm 0.95$ & $72.11 \pm 39.05$ & $6.35 \pm 3.07$ \\
\hline
\end{tabular}




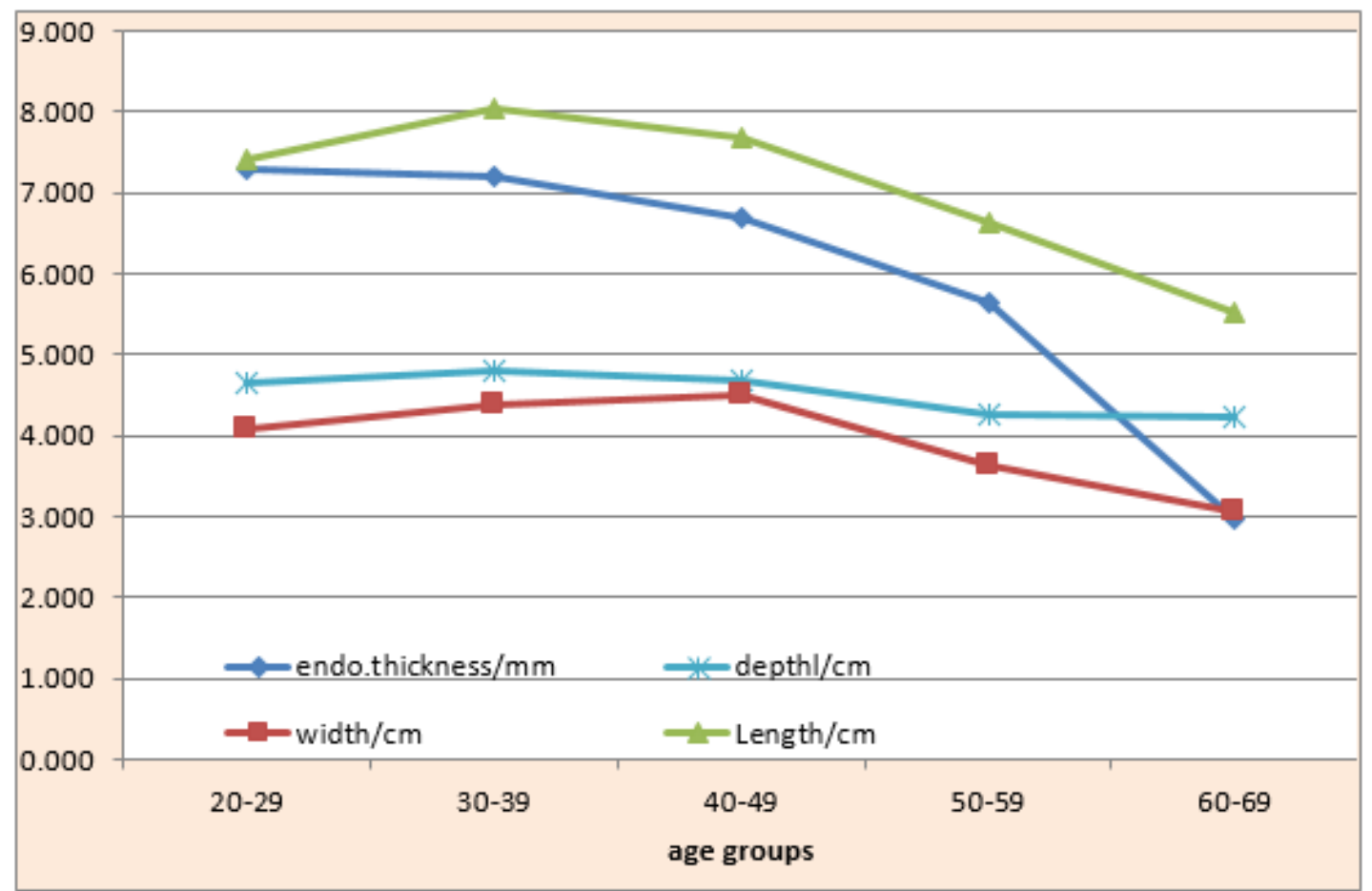

Fig.3: Graphical distribution of parameters (length, width, depth and endometrial thickness of multiparous women.

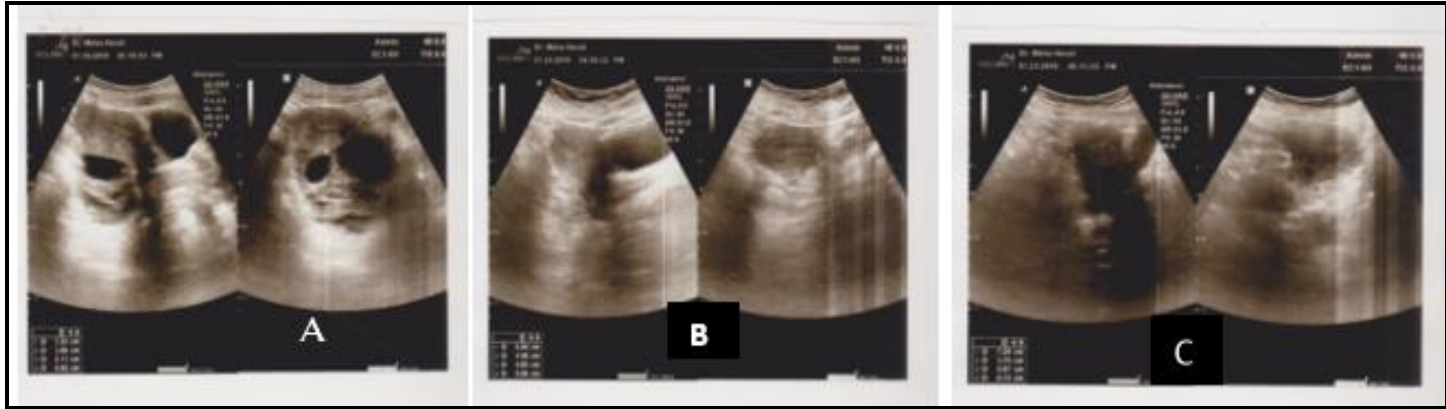

Fig.4: Uterine dimensions on a sagittal section between fundus to uterine cervix for twenty age(A), thirty age(B)and forty age(C).
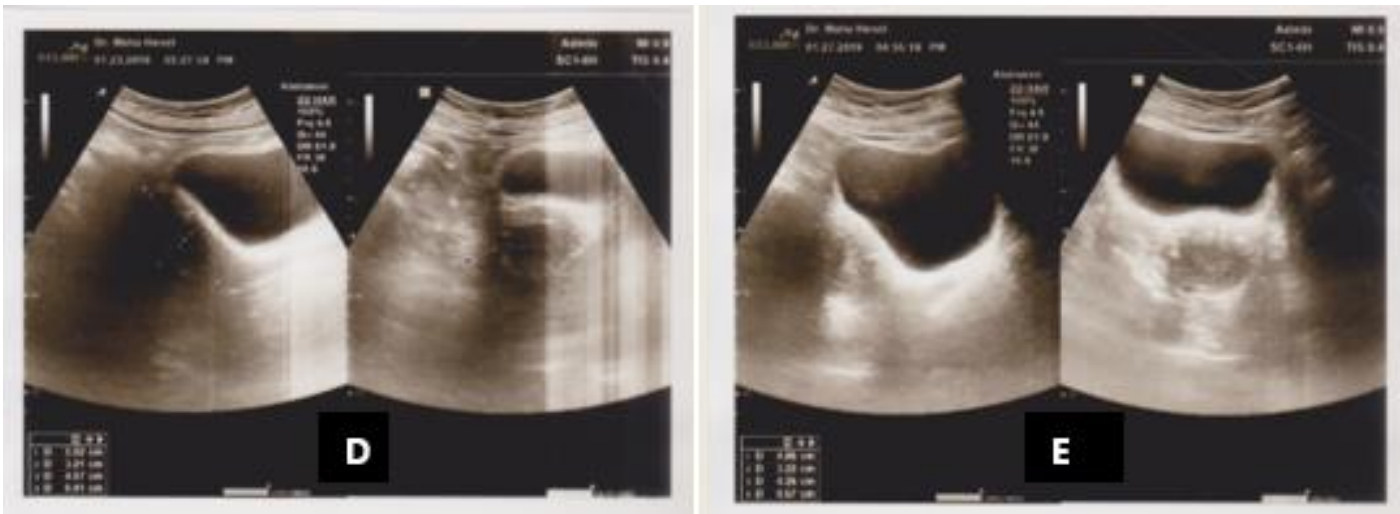

Fig.5: Dimensions of the uterus of fifty age group (D) and sixty age groups 


\section{DISCUSSION}

The sonographic technique supports good knowledge about the normal uterine dimension and helps the gynecologists to assess the health state of uterus and detect any pathological or congenital anomalies. Compared to other imaging methods, advantages of ultrasonography in this context include its affordability, ease of use, freedom from ionizing radiation, ability to readily differentiate cystic from solid masses and its role in image-guided interventional procedures. The present study compared the uterine measurement between women in different age and parity status. In this study the mean of dimension of uterus in different age groups (20-69) years of nulliparous women were; length $(5.68 \mathrm{~cm})$, width $(3.95 \mathrm{~cm})$, AP diameter or depth $(4.02 \mathrm{~cm})$, volume $(47.47 \mathrm{~cm})$ and endometrial thickness $(5.46 \mathrm{~cm})$, while the mean of uterus dimension of primiparous women for the same age groups were; length, $(6.15 \mathrm{~cm})$, width $(4.05 \mathrm{~cm}), \mathrm{AP} \quad(3.75 \mathrm{~cm})$, volume $(50.24 \mathrm{~cm})$ and endometrial thickness $(5.51 \mathrm{~cm})$. The measurement of multiparous women recorded, length $(7.28 \mathrm{~cm})$, width $(4.06 \mathrm{~cm}), \quad$ AP diameter $(4.58 \mathrm{~cm})$, volume $(72.11 \mathrm{~cm})$ and Endometrial thickness $(6.35 \mathrm{~cm})$. This finding slightly differs from Esmaelzadeh finding of means uterine size for nulliparous and multiparous women of $7.28 \mathrm{~cm} \times 4.4 \times 3.24$ and $9.08 \mathrm{~cm} \times 5.17 \mathrm{~cm} \times 4.3 \mathrm{~cm}$ respectively. This may be related to the differences in population and recesses. The present study also contrasts with wehke and Eli (2018), who reported that uterine size and volume increase with age and they recorded measurements of uterus; length $(6.74 \mathrm{~cm})$, width $(5.47 \mathrm{~cm})$ and AP diameter $(4.45 \mathrm{~cm})$. The volume recorded (75.45)

Beryl et al.,(2010) finding agreed with the present results finding that, the width of uterus decrease related to progress age in general and increased with parity and their study revealed width $2.7 \mathrm{~cm}$ in nulliparous women while $3.2 \mathrm{~cm}$ in those with more than one pregnancy.

A previous study by E.Merz et al.,(1996) in pre and postmenopausal women uterus also recorded significant differences in length and width related with parity, uterine length was $7.3 \mathrm{~cm}$ in nulliparous, $8.3 \mathrm{~cm}$ in primiparous and $9.2 \mathrm{~cm}$ in multiparous. Moawia et al.,(2013) finding of uterine size of postmenopausal Sudanese women decreases, their finding agreed with the present results of the minimum and maximum of the parameters of length $(4-9.3) \mathrm{cm}$ and agreed with present results of the minimum and maximum of width(1.5-4.9) $\mathrm{cm}$ and AP diameter( $1.6-4.4) \mathrm{cm}$. The present finding was close to Sirisena et al.,(2015), which appeared significant differences of uterine size with age and parity. They recorded mean uterine size of $(7.46 \mathrm{~cm} \times 4.22 \mathrm{~cm} \times 3.30 \mathrm{~cm}) \quad$ (Length $\times$ width $\times \mathrm{AP}$ diameter in nulliparous women, $(8.49 \mathrm{~cm} \times 4.87 \mathrm{~cm} \times 3.81 \mathrm{~cm})$ for primiparous and $(9.10 \mathrm{~cm} \times 5.3 \mathrm{~cm} \times 4.36$ $\mathrm{cm})$ for multiparous. Umar Mohamed et al,(2017) finding in their work was consonance with our finding and recorded significant differences of uterus dimension related with age and parity and revealed the uterus dimension in nulliparous $6.4 \mathrm{~cm}$, with $5.1 \mathrm{~cm}$, AP diameter $3.3 \mathrm{~cm}$, these finding were similar to the finding by Ohagwu et al.,(2007), whose established the uterine dimension for nulliparous women $5.7 \mathrm{~cm}$ length, $4.1 \mathrm{~cm}$ width, and $3.3 \mathrm{~cm}$ (Ap) diameter but did not evaluate the volume in their study, their study showed relatively strong positive correlation between uterine dimensions and age. The result of present study also agreed with those found by piiroinen (1972), in Scandinavia who established the mean of uterine dimensions for nulliparous women to be $7.6 \mathrm{~cm}$ and $2.9 \mathrm{~cm}$ for length and AP diameter respectively. 
According to Michael, the normal adult uterus measures approximately $7-9 \mathrm{~cm}$ long, $4.5-6 \mathrm{~cm}$ wide and 2.5-3.5 cm depth (15), Their findings were very closest to the present findings. Olayemi et al. (2002) evaluated the effect of parity on uterine involution and the analysis revealed positive correlation between parity and uterine diameters and uterine volume. Our result contrast with that of Holt et al. (1994) which showed the uterine dimensions for nulliparous to be $7 \mathrm{~cm}, 4 \mathrm{~cm}, 4 \mathrm{~cm}$ for length, width, and AP diameter respectively. It also contrasts with the study by Waldroup and Liu (1997). The result of our study does not agree with that of sanders (1991), which showed the dimension of uterus as $6 \mathrm{~cm}, 4 \mathrm{~cm}, 4 \mathrm{~cm}$ for length, width, and AP diameter. Ajay et al.(2016)were established the uterine dimensions recorded increase in parous than nulliparous women and the uterus dimensions increase at reproductive age and later decrease after 49 years old gradually with progress age to postmenopausal, these findings agree with our finding, there is significant reduction in all uterine measurements and endometrial thickness in age from 49-60years age group women and multiparous women have greater dimension and volume than the primiparous and nulliparous. The difference in uterus measurements obtained in the present study from those reported in other countries may be due to the impact of factors such as race, heredity, environment, and diet. The increased uterus dimensions refer to changes effect during recurrent pregnancy on the size, length smooth muscle cells of myometrium, So during the first few months of pregnancy the uterine walls become thicker accompanying the increase in size and number of blood vessels and lymphatics. The direct correlation between age and uterus size was seen in present study may be due to changes over a woman's lifespan in ovarian estrogen secretion. Uterine growth continuous during the reproductive years of woman's life and ceases at menopause, ultimately regressing in size to approximate its pubertal form by Waldroup and Liu JB (1997)

\section{REFERENCES}

Ajay M. Parmar, D.P.Agarwal, Nipa Hathila, T.C.singel. (2016). sonographic mesurements of uterus and its correlation with different parameters in parous and nulliparous women. international journal of medical science and education.issn2349-3208; Vol.(3);P:306-10; issue:3;july-sep.

Beryl R. Benacerraf, MD, Thomas D. Shipp, MD, Jennifer G. Lyons, $\mathrm{MPH}$, and Bryann Bromley, MD(2010).Width of the normal uterine cavity in premenopausal women and effect of parity. Obstetrics \&gynecology. 116: 305-10.

Danddolu V. singer RMD, lidickerJMS. (2010).BMI and uterinesize:is there any relationship?. International journal of gynaecoloical pathology. Vol, 29(6):568-571.

Ezmaelzadeh S, Rezaei N. and HajiAhmadi.(2004)Normal uterine size in women of reproductive age in northern Islamic republic of iran. Eastern Mediterranean Health journal, 10(3):437-441.

Holt SC, Levi CS, Lyons EA, Lindsay DJ, Dashefsky SM. (1994).Normal anatomy of female pelvis. In: Callen PW, editor. Ultrasonography in Obstetrics and Gynecology. $3^{\text {rd }}$ ed. Philadiliphia: WB, saunders; .P.548-68.

Merz E, Miric-Tesanic D, Bahlmann F, Weber G, Wellek S. (1996).Sonographic size of the uterus and ovaries in pre- and postmenopausal women. Ultrasound obstet Gynecol. 7:38-42. 
Merz E, Tesanic MD,Bawmann F, Weber G, Wellek S. A. 1995. Transvaginal sonographic study of uterine size; Ultrasoun in obstetrics and gynecology; $\operatorname{vol}(7), 1: 38-42$.

MichaelA. (2013).Ultrasound in infertility; Web Book; 2008. Available from: http://www. Drapplebaum. Com/normal. [Last assessed on 2013 Mar 08.

Mihu D and Mihu C.M. (2011): Ultrasonography of the uterus and ovaries. Medical ultrasonography, 13 (2):249252.

Milli AB, Thomas RG, Thomas RG. 2013 uterus anatomy. medscape. Available from: http// www. Emedicine. Medscape. com/ article/1949215.\{Lastassessedon 2013 nov 08.

Moawia Gamersddin, Maha Haj Ali, Mohamed yousif, (2013). Sonographic size of uterus in postmenopausal Sudanese women. IOSR Journal of dental and medical sciences (IOSRJDMS); Volume 6, Issue 2(MarApr); pp 65-67.

Ohagwu cc, Agwu KK, Po. (2007) .real time sonographic assessment of common uterine sizes shapes and positions in Nigeria. J Expt Clin Anat; 6:416.

Olyemi O, Omigbodun AA, Obajimi MO, Odukogbe AA, Agunloye AM, Aimakhu, CO, (2002).Ultrasound assessment of the effect of parity on postpartum uterine involution. J Obstet Gynaecol; 22:381-4.

Piiroinen O. (1972).Ultrasonic determination of uterine size. The Scandinavian association of obstetrician and gyaecologist.seventeenthcongres s.Aarhus;.P.43.
Sanders RC. (1991).Clinical sonography: A PracticalGuide. $2^{\text {nd }}$ ed. Boston: little- Brown; .P.45-6.

Sirisena U.A.I, Jwanbot D.I., Pam S.D, Goshit S.J, Samson R.I. (2015). Normal uterine size in women of reproductive age in jos, Nigeria: An Ultrasonographic Investigation. Journal of health, medicine and nursing.vol (19); 71-75.

Testa AC, Bourne TH. Characterising pelvic masses using ultrasound. Clin Obstet Gynaecol 2009; 23:725-38.

Timor-tritsch IE, Monteagudo A, Brown GM. (1994); Endovaginal sonographic valuation of the obstetrics and gynecology patient. In: Callen $\mathrm{PW}$, ed. Ultrasonography in obsteteics and gynecology, $3^{\text {rd }}$ ed. Philadelphia,WB Sauders, 1994:5

Umar UM, Isyaku K, Adamu YM, Abubakar SA, Kabo NA, Nura I, (2017): Sonographic measurement of uterine dimensions in healthy nulliparous adults in Northwestern Nigeria. Sahel Med J; 20:1-7.

Waldroup L, Liu JB, (1997).Sonographic anatomy of the female pelvis. In: Berman MC,Cohen HL, eds. Diagnostic medical sonography: obstetrics and gynecology.Philadelphia, Lippincott,:51-9.

Wehke.C, Eli. S. (2018). Sonographic Evalution of the Normal uterine size and volume amongst women of ages 18-50 years at the university of Port Harcourt teaching hospital. Greener journal of medical sciences, Vol (8); 3.pp.027-050. 